\title{
Policy for Therapeutic Massage in an Academic Health Center: A Model for Standard Policy Development
}

\author{
MONICA MYKLEBUST, M.D., ${ }^{1}$ and JOANNE ILER, M.A. ${ }^{2}$
}

\begin{abstract}
Context: Massage is the most common complementary and alternative medicine (CAM) therapy used in hospitals in the United States. As such, it is often the first CAM therapy to be integrated with conventional medicine. However, few academic medical centers have a written standard policy to guide this integration. This lack of standard policy may impede institutions from offering massage therapy as a clinical service, and may put health care professionals and institutions at risk through a failure to clearly address criteria for practice credentials or malpractice liability.

Objective: To create a clinical policy for therapeutic massage that may be used as a template for development of policy in academic health centers.

Results: We present a clinical policy for therapeutic massage, developed by the University of Michigan Health System, that defines therapeutic massage, provides guidelines for the credentialing and professional conduct of massage therapists, lists indications and contraindications for therapeutic massage, and addresses malpractice in accordance with the specific culture and needs of academic health centers. This policy was created by health care professionals after review of existing evidence and consideration of national criteria for massage therapy. This policy is intended to be used as a template for the development of a standard policy for therapeutic massage by health system administrators, medical directors, and massage professionals, to support the integration of therapeutic massage within their institutions.

Conclusions: With minor modifications of this policy by individual institutions, adoption of this policy may facilitate the thoughtful integration of this CAM therapy into academic health care settings, meeting the unique requirements of academic health care institutions while serving the needs of patients.

\section{INTRODUCTION}

$\mathbf{I}^{\mathbf{n}}$ n 1997, adults in the United States made an estimated 114 million visits to massage therapists. Visits to chiropractors and massage therapists combined represented $50 \%$ of all visits to practitioners of complementary and alternative medicine (CAM). ${ }^{1}$ In 2003, the American Hospital Association's survey of more than 6000 hospitals identified massage therapy as the most common CAM therapy used in hospitals in the United States (78\% of all therapies). ${ }^{2}$ Among hospitals' key reasons for offering massage were patient demand and clinical effectiveness.

Patients often request massage and staff members would like to offer it. This is consistent with unpublished findings of a 2005 survey conducted by Myklebust* within the University of Michigan Health System (UMHS). The survey was sent to clinical department administrators, inpatient nursing managers, ambulatory care site managers, and medical directors. Of 60 sites surveyed, $16 \%$ offered some form of massage and an additional $44 \%$ wanted to be able to offer massage to their patients.

Despite their increasing use in conventional medicine, standard policies to support the integration of practices such as therapeutic massage are lacking. In a survey of 19 hos-

\footnotetext{
${ }^{1}$ University of Michigan Integrative Medicine, Clinical Services, Department of Family Medicine, University of Michigan, Ann Arbor, MI.

${ }^{2}$ Private practice, Ann Arbor, MI.

*Myklebust M. Inventory of Integrative Medicine Services.
} 
pitals for credentialing and malpractice liability policies governing the integration of CAM therapies and providers, Cohen and associates found no consistency in approaches to licensure or malpractice liability in developing models of integrative care. ${ }^{3}$ A random sampling of 39 academic health centers done in 2005 found that while 23 offered CAM therapies including massage, none had a written policy to guide credentialing practices and malpractice liability for such therapies. ${ }^{4}$ In a 2004 study focusing on credentialing methods used by academic health centers for CAM providers, Nedrow found inconsistency in guiding principles, misunderstanding of CAM licensure, and wide variation in approaches to incorporation of CAM providers into the healthcare setting. ${ }^{5}$

National criteria exist to guide the certification of massage therapists, their education, and practice standards. The National Certification Board for Therapeutic Massage and Bodywork (NCBTMB) has developed practice standards and certifies massage practitioners who meet these standards. ${ }^{6}$ The Commission on Massage Therapy Accreditation, recognized by the U.S. Department of Education, accredits massage therapy training programs on the basis of specific criteria. ${ }^{7}$ Additionally, as of November 2006, 37 states and the District of Columbia had enacted legislation governing the profession of massage therapy that included educational, examination, and licensing requirements. ${ }^{8}$ At this writing, legislation requiring the licensing of massage therapists in Michigan remains pending. ${ }^{9}$ However, a tool to guide the incorporation of national criteria for massage therapy into the culture and specific needs of academic medicine is needed.

We present a clinical policy for therapeutic massage developed by the UMHS. This policy is intended to be used as a template for the development of standard policy by health-system administrators, medical directors, and massage professionals. Standard policy for therapeutic massage may facilitate the provision of high-quality therapeutic massage services for patients, while minimizing the risks of these services to health-care professionals and institutions.

\section{METHODS}

In the spring of 2004, massage therapists and other professionals involved with the provision of therapeutic massage at the UMHS were contacted with the goal of establishing a process for integration of massage services within the health system. Ten people, including administrators, physicians, nurses, and 5 massage therapists, participated in initial discussions that informed the process of establishing standards to support the provision of high-quality massage therapy services. First, a survey was conducted to assess existing massage practices within the institution. It included demographic data about the therapists and clients, types of massage provided and where provided, how massage services were documented, and fees. The survey revealed that although massage was offered in several areas within the institution, no standard policy guided its practice, and that the people who provided massage were unaware of each other's work.

Over the next 9 months, informed by professional standards set by the national massage therapy community, the University of Michigan Integrative Medicine Clinical Services Massage Collaborative, worked to craft language to define therapeutic massage and its indications and contraindications, and to target qualifications for massage therapists that specifically meet the needs of an academic health center. Professional standards and procedures to support the practice of therapeutic massage were also developed. To guide every aspect of the development of this policy, the collaborative evaluated evidence from the peer-reviewed medical literature and systematic reviews. ${ }^{10-16}$ Respected massage-therapy texts, research literature from the profession of massage therapy, and reputable related websites were also reviewed. ${ }^{17-22, \dagger}$ Common patient symptoms and conditions treated by massage were considered.

Collectively, the members of the Massage Collaborative had professional training in massage, family medicine, nursing, social work, medical-recordkeeping, and teaching. This grassroots approach offered an opportunity to develop a common language and to write materials that represent a wide range of ideas and perspectives, and resulted in interdisciplinary support. Guided by the NCBTMB national standards, and using established UMHS policy format as well as group consensus, the collaborative successfully completed the Policy for Therapeutic Massage in an Academic Health Center. It was approved by the UMHS legal counsel and the Executive Committee on Clinical Affairs, which governs clinical practice at the UMHS.

\section{RESULTS}

\section{Policy statement}

The OMHS policy for therapeutic massage states that "It shall be the policy of the University of Michigan Health System (UMHS) that Nationally Certified Massage Therapists, with appropriate qualifications and specialty certifications, may practice therapeutic massage as an integrative approach to patient care for the purpose of symptom management (i.e. decrease pain, anxiety, and fatigue), to provide relaxation and furnish self-care techniques that facilitate the body's innate healing processes to restore homeostasis and health."

\section{Policy purpose}

The policy states that its purpose "is to describe the clinical application of therapeutic massage within the University of Michigan Health System."

${ }^{\dagger}$ Touch Research Institutes, University of Miami School of Medicine. Online document at: www.miami.edu/touch-research/ Accessed November 10, 2006. 


\section{Definition of massage}

The policy defines therapeutic massage as "the systematic and scientifically based manipulation of the soft tissues of the body by a trained professional. It is organized intentional touch applied with sensitivity and compassion guided by a clearly formulated procedural plan. Goals of massage therapy include: to identify and eliminate hyperirritability in muscle and fascia, to reduce soft tissue pain and spasm, to restore lymph and blood circulation to tissues, restore normal range of motion and flexibility, release fascial and soft tissue adhesions, reduce or eliminate the underlying causes of chronic pain patterns, stimulate inactive muscle tissue, promote relaxation, and to teach self-care techniques for lasting pain relief. As part of an integrative approach to care, therapeutic massage is noninvasive and complementary to conventional medical treatment."

The policy defines chair massage as massage "given on a portable massage chair, designed for comfort and support. A certified massage therapist uses her/his hands and forearms to apply massage techniques to the head, neck, shoulder, back, arm and hand muscles of the patient. The patient remains fully clothed."

The policy defines table massage as massage "given in a private room on a massage table with a face cradle designed for comfort and support. The patient undresses to their comfort level, in privacy, and lies on the table where sheets and blankets are provided. The patient remains covered during the massage except for the area of the body that the massage therapist is working. Massage lotion or oil may be used."

\section{Massage indications}

Indications for therapeutic massage specified in the policy statement are musculoskeletal pain, strain, spasm, and tightness; stress; tension headache; jaw (temporomandibular joint) dysfunction; fatigue; anxiety; and sleep disturbance.

\section{Credentials}

Qualifications for massage therapists in the UMHS policy statement are guided by national standards set by professional massage-therapy organizations. Additional qualifications needed for the practice of massage in an academic health center are included. The qualifications adopted by the collaborative are listed in Table 1.

\section{Referral procedures}

To ensure the highest quality of care, communication between the health-care provider(s) and the massage therapist is optimal. However, the UMHS policy for therapeutic massage does not require a physician referral.
Table 1. University of Michigan Health System Massage-Therapist Qualifications

Graduation from a COMTA ${ }^{\mathrm{a}}$-accredited school of massage therapy offering a minimum of 650 hours of education including: pathology, anatomy and physiology, and ethics.

Current certification with the National Certification Board for Therapeutic Massage and Bodywork (NCBTMB) as well as local certifications if applicable

Membership in good standing with one of the following, nationally recognized professional massage and bodywork associations: (1) American Massage Therapy Association (AMTA), or (2) Associated Bodywork and Massage Professionals (ABMP)

Proof of liability insurance in the amount of $\$ 2$ million/each occurrence with $\$ 6$ million aggregate coverage through AMTA or ABMP

Minimum of 2 years experience as a massage practitioner beyond formal training, or comparable experience in the healing arts

Experience working in a hospital or medical setting, comfort in working with and has a documented capacity to work with persons who are ill, and knowledge of medical terminology, diagnoses, and therapies

Evidence of training in patient confidentiality, including HIPAA $^{\text {b }}$ privacy training, provided by the therapist's institution, demonstration of an understanding of the importance of patient privacy, and signature of an institutional confidentiality agreement

Provision of three references regarding: (1) character, (2) professional competence, (3) client

Demonstration of massage skills by giving a massage to an evaluating member of the health-care team

The ability to read, understand, and uphold the Code of Ethics and Standards of Practice of the National Certification Board for Therapeutic Massage and Bodywork

The provision upon request of proof of certification for specific treatments (i.e lymph drainage, CranioSacral therapy, infant massage)

${ }^{a}$ COMTA, Commission on Massage Therapy Accreditation. COMTA is the federally recognized, independent, nonprofit accrediting body for the massage-therapy profession.

bHealth Insurance Portability and Accountability Act of 1996.

\section{Contraindications and cautions}

Under the UMHS policy, therapeutic massage is locally contraindicated in or near areas of infection, tumors, or incisions. Other contraindications include but are not limited to impairment by alcohol or drugs, the presence of contagious rashes, or persons and failure of the patient to consent to massage therapy. Pressure considerations, site restrictions, and positioning adjustments may require modifications of the massage procedures and techniques.

\section{Professional standards and ethics}

The UMHS policy states that "the massage therapist will know, understand, and abide by the standards of practice and ethics as defined by the National Certification Board for Therapeutic Massage and Bodywork (NCBTMB) and the professional massage association to which the therapist be- 
longs. The massage therapist will have certification in the modality of massage therapy utilized. Proof of certifications shall be required and on file with the institution. The massage therapist will follow the University of Michigan Hospital and Health Center (UMHHC) guidelines."

\section{Attire and appearance of massage therapist}

The UMHS policy states that "the massage therapist will dress in clean slacks or skirt and shirt. Close-toed shoes must be worn. No finger rings may be worn while giving massages. Jewelry should be kept to a minimum. No scent in the form of perfumes or lotions is to be worn. Fingernails are to be shorter than the fingertips, filed and beveled so there are no sharp or rough edges."

\section{Massage therapist agreement/contract}

The Massage Agreement/Contract is a standard document used by the UMHHC for persons employed as independent contractors, and was modified in consultation with legal council of the hospital and the University of Michigan Integrative Medicine Clinic.

\section{Massage therapy session}

According to the UMHS policy for therapeutic massage, patients may refer themselves or be referred by their health care provider. The policy specifies that "prior to an initial massage, the patient will complete a health history form providing information on current medications, surgical and injury history, infections, areas to be avoided and other conditions that may affect the treatment parameters. Treatment plan including goals of therapy and techniques to be used will be discussed with the patient prior to treatment. Signed consent is required prior to treatment. Appropriate self-care techniques, within the therapist's scope of practice, will be demonstrated for the patient and written materials illustrating these same techniques will be provided to the patient. Individualized treatment protocol will be documented using standard documentation format and provided to the patient's medical record. The massage therapist will be overseen by an identified physician in the department who will review all treatment plans and be available for consultation."

\section{DISCUSSION}

Massage is the most common CAM therapy used in hospitals in the United States. ${ }^{2}$ Given that requests for this service are likely to continue to grow, institutions must move forward with the development of standard policy guidelines for its use.

However, despite the existence of national criteria that guide the practitioner education and certification and the professional practice of massage in general, they need to be adapted to fit the unique needs of academic medical centers. The policy presented in this paper is intended to be universally applicable, with modest modifications by individual institutions to create the best fit to their purposes and practices. For example, institutional guidelines stating specific language and format for policy development may vary, and it is recommended that users of this policy investigate such guidelines at their local institutions. Also, the exact process for approval of such policies differs among institutions. State legislation regarding the licensing and other regulatory aspects of massage vary greatly and need to be considered. Additionally, referral practices, documentation of visits, fees, and insurance reimbursement vary by region. At the UMHHC, most clients are self-referred, documentation occurs in the paper chart but not in the electronic record, and both fee-for-service and insurance-coverage payment systems are utilized. Indications for massage vary with regard to the level of evidence supporting its benefits. To guide their practice, clinicians may find it useful to augment the massage-therapy policy described here with a document that outlines levels of evidence relating to specific indications for such therapy common to their patient populations. While benefits of employing massage therapists formally or as contracted employees will vary, both means are used at the University of Michigan. Oversight of the massage therapist by a physician is often advised by institutional general counselors. Aspects of the policy that can be generalized include: policy purpose, definitions, massage-therapist qualifications; indications, contraindications and cautions for therapy; professional standards and ethics; therapists' attire and appearance; and inclusion of an outline of a massage therapy session. The massage-therapist qualifications included here specifically consider the unique needs and requirements for practicing therapeutic massage within an academic health care setting.

Cohen offers insightful commentary regarding the "many competing values at stake in institutional assimilation of appropriate CAM therapies." 23 He points out that "safety, efficacy, and benefit of therapy to the patient; patient autonomy and the right to make informed choices about therapeutic options; medical pluralism; and accountability are but a few issues to be weighed in institutional discussions." 23 It is our hope that standard therapeutic-massage policy will facilitate the thoughtful integration of this CAM therapy into academic health-care settings, addressing these potentially competing values while serving the needs of patients.

\section{ACKNOWLEDGMENTS}

Monica Myklebust, M.D., and Joanne Iler M.A., M.T., N.C.T.M.B., wish to acknowledge other members of the University of Michigan Integrative Medicine Clinical Services Massage Collaborative, the massage therapists David 
Glenn, B.S., L.S.W., M.T., Diane Kremer, R.N., M.T., N.C.T.M.B. and Debbie Upton, M.T., N.C.T.M.B.

\section{REFERENCES}

1. Eisenberg DM, Davis RB, Ettner SL, et al. Trends in alternative medicine use in the United States, 1990-1997: results of a follow-up national survey. JAMA 1998;280:1569-1575.

2. Ananth S. Health Forum 2003: Complementary and Alternative Survey of Hospitals. Online document at: www.ahadata. com

3. Cohen MH, Hrbek A, Davis RB, et al. Emerging credentialing practices, malpractice liability policies, and guidelines governing complementary and alternative medical practices and dietary supplement recommendations: A descriptive study of 19 integrative health care centers in the United States. Arch Intern Med 2005;165:289-295.

4. $\overline{\text { Cohen } \mathrm{MH}}$, Sandler L, Hrbek A, et al. Policies pertaining to complementary and alternative medical therapies in a random sample of 39 academic health centers. Altern Ther Health Med 2005;11:36-40.

5. Nedrow A. Status of credentialing alternative providers within a subset of U.S. academic health centers. J Altern Complement Med 2006;12:329-335.

6. National Certification Board for Therapeutic Massage and Bodywork. Standards of Practice. Online document on: www. ncbtmb.com/standards_of_practice.html Accessed August 30, 2006.

7. Commission on Massage Therapy Accreditation. Online document at: www.comta.org/about.html Accessed August 30, 2006.

8. Laws and legislation. Massage Magazine 2006;124:124-125.

9. State of Michigan. House Bill 5218. Online document at: www.legislature.mi.gov/(r01pftvh2fy3njzjqpy0b2u0)/mileg. aspx page $=$ getObject\&objectName $=2005-H B-5218$ Accessed August 30, 2006.

10. Moyer CA, Rounds J, Hannum JW. A meta-analysis of massage therapy research. Psychol Bull 2004;130:3-18.

11. Cherkin DC, Sherman KJ, Deyo RA, et al. A review of the evidence for the effectiveness, safety, and cost of acupuncture, massage therapy, and spinal manipulation for back pain. Ann Intern Med 2003;138:898-907.

12. Cassileth B, Vickers A. Massage therapy for symptom control: Outcome study at a major cancer center. J Pain Symptom Manage 2004;28:244-249.
13. Corbin L. Safety and efficacy of massage therapy for patients with cancer. Cancer Control: J Moffitt Cancer Center 2005;12: 158-164.

14. Dillard MH, Knapp S. Complementary and alternative pain therapy in the emergency department. Emerg Med Clin North Am 2005;23:529-549.

15. Field T. Massage therapy effects. Am Psychologist 1998;53: 1270-1281.

16. Furlan AD, Brosseau L, Imamura M, Irvin E. Massage for lowback pain. Cochrane Database Syst Rev 2002;2:CD001929.

17. National Center for Complementary and Alternative Medicine, National Institutes of Health. Online document at: http://nccam.nih.gov/health/massage/ Accessed November 17, 2006.

18. American Massage Therapy Association Foundation Massage Therapy Research Database. Online document at: www. amtafoundation.org/researchdb.html Accessed November 10, 2006.

19. Lowe W. Functional Assessment in Massage Therapy: A Guide to Orthopedic Assessment of Pain and Injury Conditions for the Massage Practitioner. Bend, OR: Orthopedic Massage Education \& Research Institute, 1997.

20. MacDonald G. Massage for the Hospital Patient and Medically Frail Client. Philadelphia: Lippincott Williams \& Wilkins, 2005.

21. Travel J, Simons L. Travell \& Simons' Myofascial Pain and Dysfunction: The Trigger Point Manual, 2nd ed. Philadelphia: Lippincott Williams \& Wilkins, 1999.

22. Werner R. A Massage Therapist's Guide to Pathology. Philadelphia: Lippincott Williams \& Wilkins, 1998.

23. Cohen MH, Harmonizing the cacophony: commentary on "Status of credentialing alternative providers within a subset of U.S. academic health centers." J Altern Complement Med 2006;12:337-339.

Address reprint requests to: Monica Myklebust, M.D. University of Michigan Integrative Medicine Clinical Services Department of Family Medicine University of Michigan 1801 Briarwood Circle, Bldg.\#10 Ann Arbor, MI 48108

E-mail:mmyklebu@umich.edu 
